\title{
Da revisão de texto à revisão de texto crítica: uma nova perspectiva profissional ${ }^{*}$
}

\author{
Harrison da Rocha ${ }^{1}$ \\ Carina Melo da Silva ${ }^{2}$
}

\section{Resumo}

A Revisão de Texto não envolve apenas a adequação do gênero a ser revisado à modalidade-padrão da língua portuguesa. Pensar assim torna a atividade superficial, uma vez que essa prática se insere em uma subjetividade cujos elementos se revelam muito mais complexos. Por isso a importância deste trabalho para contribuir na transformação da atividade de Revisão de Texto em uma perspectiva crítica. De outra parte, a Revisão de Texto possui função social. Desse modo, deve-se considerar, veementemente, que tal prática alcança horizontes que vão além do texto escrito. Sendo assim, sua prática precisa ser analisada a partir de visões macros, que considerem as relações suscitantes dessa atividade - entre linguagem e sociedade; linguagem e poder; linguagem e identidade. Dessa forma, o objetivo desta pesquisa é repensar a atividade de Revisão de Texto em uma perspectiva crítica para acompanhar as novas mudanças nos estudos da linguagem e aplicá-las nas atividades que envolvem análise de texto. A fundamentação teórica baseia-se, principalmente, na Análise de Discurso Crítica (ADC), nos trabalhos de Fairclough (2001, 2003); na Teoria dos Gêneros Discursivos, Bakhtin (1997) e Marcuschi (2002).

Palavras-chave: Revisão de texto profissional. Teoria crítica. Multimodalidade.

\footnotetext{
* Pesquisa realizada no Programa de Iniciação Científica (PIC) do Centro Universitário de Brasília (UniCEUB).

1 Mestre e doutorando em Linguística pela Universidade de Brasília (UnB). Especialista em Língua Portuguesa pela UnB. Coordenador dos cursos de pós-graduação lato sensu em Língua Portuguesa do UniCEUB. Professor de Língua Portuguesa e Linguística da mesma instituição. Atualmente desenvolve pesquisas nas áreas de Análise de Discurso Crítica, Multimodalidade, Letramento e Revisão de Textos. Autor de artigos científicos e livros nessas áreas.rocha123@gmail.com.

2 Graduada em Letras Português/Inglês e Respectivas Literaturas - Centro Universitário de Brasília - UniCEUB. carinamsilva@gmail.com.
} 


\section{Introdução}

Considerar a prática de Revisão de Texto um processo simplesmente mecânico é um pensamento errôneo e primitivo. Sabe-se que um texto envolve muito mais do que as regras gramaticais; ele engloba contextos subjetivos, sociais, históricos, linguísticos e cognitivos. Isso porque, na construção de um texto, existem tantos elementos envolvidos quanto é a complexidade deles. Porém, pode-se dizer que, sem um desses elementos, em especial, não há como se ter sequer uma frase.

Seja qual for o tema, seja qual for a intenção ao se produzir um texto, ele vai ser consequência do ponto de vista, do contexto, do sentido, enfim dos conhecimentos de seu produtor, e tudo isso faz parte de uma construção. É exatamente do que trata a identidade de um indivíduo, de um processo de construção ao longo da vida.

Pelo fato de que a Revisão de Texto vai muito além de um trabalho técnico ou da aplicação das regras gramaticais, é preciso que haja entre produtor e revisor a negociação do sentido, em que ambos possam chegar a um ponto em comum em relação às "intenções" do texto.

Por isso, o foco principal de nossa pesquisa está na busca da transformação da perspectiva clássica de Revisão de Texto que explora apenas a modalização na perspectiva da norma-padrão para associá-la às novas teorias dos estudos da linguagem em uma perspectiva crítica. O objetivo geral da pesquisa é contribuir para a mudança da Revisão de Texto que explora apenas a modalização da norma-padrão para associá-la às novas teorias dos estudos da linguagem em uma perspectiva crítica. Dessa maneira, desenvolvemos três questões de pesquisa que nortearão todo nosso trabalho:

1 De que maneira é praticada a Revisão de Texto em diferentes setores em que ela é trabalhada?

2 Quais as disparidades existentes entre a Revisão de Texto Monomodal e a Revisão de Texto Crítica?

3 Qual arcabouço teórico embasado na Análise de Discurso Crítica pode ser criado para esta nova proposta de revisão de texto? 
Tem havido muita discussão sobre as diferenças entre pesquisa quantitativa e pesquisa qualitativa (BAUER; GASKELL, 2002). Enquanto a primeira lida com os números, usa modelos estatísticos para explicar os dados e é considerada hard, a pesquisa qualitativa lida com interpretações das realidades sociais e é considerada soft.

A profundidade da metodologia qualitativa ainda vai além das perspectivas que o objeto pesquisado suscita. Ela amplia também a possibilidade da análise de dados para além do texto, considerando vários dados que complementam os objetivos de uma pesquisa.

Por todas essas características, neste trabalho adotaremos o método qualitativo de pesquisa, já que o objetivo maior, além de relatar o que se passa na prática da Revisão de Texto, é abrir possibilidades de mudança.

\section{A Revisão de Texto na perspectiva tradicional}

Esta seção tem como objetivo principal rever a prática da Revisão de Texto clássica, tradicional e monomodal, que se preocupa apenas com o escrito. Para isso, faremos uso de materiais que respaldam este tipo de revisão.

Entende-se revisão como o ato de revisar. Revisar um texto, uma carta, uma produção literária. A palavra revisar tem como significado: visar de novo; ter novamente sob os olhos; fazer inspeção de; apor visto a; ler (texto), a fim de consertar-lhe possíveis erros, sejam eles relativos à estrutura do texto (redação, digitação, tipografia etc.) ou ainda relativos ao conteúdo; emendar, corrigir, rever. (HOUAISS, 2001, p. 2.453). Já a palavra revisão, que tem sua origem na terminologia revisar, significa: ato ou efeito de rever ou revisar; nova leitura, mais minuciosa, de um texto; novo exame; exame minucioso das provas de impressão a fim de fazer-lhes as necessárias emendas no confronto com os originais; alteração, modificação de uma coisa qualquer, em consequência de se ter reconsiderado, repensado o assunto; reavaliação, reconsideração. (HOUAISS, 2001, p. 2.453). 
A revisão acontece quando o autor de uma produção textual sente a necessidade de rever aquilo que foi produzido, com a intenção de aperfeiçoar seu trabalho. Esse acontecimento é de suma importância, pois o autor, que tem contato direto com sua produção, muitas vezes não se atém a possíveis erros de ordem gramatical, ortográfica, discursivas e ideológicas existentes em sua própria obra.

Em uma empresa, é perfeitamente possível definir o que faz um revisor, ou melhor, quais são as etapas a executar para que se chegue a um resultado satisfatório de revisão. Primeiramente, deve-se definir se será revisão ou copidesque (revisão de originais). Logo depois, é hora de "pôr a mão na massa". O revisor começa analisando o texto a partir de seus aspectos formais (acentuação, pontuação, sintaxe etc.).

Essa maneira de revisar se preocupa apenas com a correção ortográfica e gramatical do texto, norma-culta, erroneamente chamada de norma-padrão, e que prioriza apenas o gênero escrito, imposto pela conhecida Gramática Tradicional (GT). Com esse sistema baseado na GT, temos uma revisão de texto mecânica calcada apenas na decodificação de signos e regras. Se um revisor tem arcabouço teórico em regras e exceções dos manuais de produção textual, logo é considerado um bom revisor e apto à pratica dessa modalidade de revisão.

É justamente neste ponto que nossa pesquisa se aprofunda. Preocupados com o tipo de revisão que é feita atualmente e com as preconizações dos revisores de texto, surgiram alguns questionamentos. A que se propõe um revisor? Que tipo de trabalho ele desenvolve? Quais são suas intenções na correção de uma obra? Que tipo de material teórico norteia essa revisão? Qual o seu objetivo ao revisar um texto?

Com a primeira questão de pesquisa respondida, seguimos para o próximo tópico a ser dirimido. Por meio de teorias críticas (Análise de Discurso Crítica), fazendo-se uma coesão interdisciplinar com a ideologia, propomos rever a atividade de revisão de texto autônoma, baseada apenas em estruturas formais, que alija os outros meios semióticos presentes no gênero discursivo a ser revisado. Isso não significa que estamos desconstruindo uma atividade secular já existente. Pelo con- 
trário, pretendemos com isso, ampliar seu escopo de ação para torná-la adaptada à pós-modernidade, palco de tantos recursos tecnológicos, e de tantas mudanças.

\section{Fundamentação teórica}

Apresentaremos as teorias que formulam a base teórica de nossa pesquisa. Como foco central, temos a Análise de Discurso Crítica, apresentada por Norman Fairclough $(2001,2003)$ e Ingedore Koch (2005) e como não é possível dissociar elementos como: Ideologia, Teoria dos Gêneros Discursivos e Multimodalidade da ADC, uma vez que nosso corpus é constituído de um Gênero Híbrido, apresentaremos breves definições a respeito delas respaldadas pelos autores: Voloshinov (1990); Thompson (2000); Bakhtin (1997); Marcuschi (2002) e van Leeuwen (2000).

\subsection{A revisão como prática de texto, prática discursiva e prática social}

O papel social da Revisão de Texto é, principalmente, destrinchar o que está escrito - ou representado - buscar o sentido mais amplo para chegar à prática social, considerando o contexto - e, quando se fala em contexto, quer-se dizer absolutamente tudo: etnia, classe social, nível de letramento etc. - em que se insere seu produtor. Desse modo, devemos estudar a Revisão de Texto em uma perspectiva social.

Norman Fairclough (2001), em sua obra Discurso e mudança social, cujos objetivos são reunir a análise linguística, à teoria social e desenvolver abordagem para análise de discurso na investigação de mudanças sociais, apresenta-nos o quadro tridimensional do discurso para estudar a linguagem e sociedade, pois, segundo ele, todo evento discursivo é simultaneamente um texto, um exemplo de prática discursiva e um exemplo de prática social. Vejamos o esquema que pode ser aplicado à Revisão de Texto: 


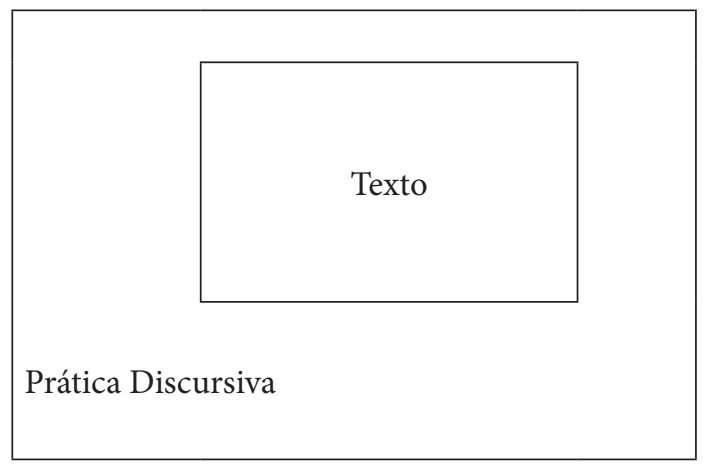

Prática Social

Com tal quadro, o autor reúne três dimensões indispensáveis na análise do discurso: a tradição textual - que abrange a Linguística; a tradição macrossociológica de análise da prática social em relação às estruturas sociais; a tradição interpretativa - que considera a prática social como algo que as pessoas produzem ativamente e compartilham. A parte que trata da análise textual é denominada descrição, enquanto as partes que englobam a prática discursiva e a prática social das quais o discurso faz parte são denominadas interpretação.

A prática social tem várias orientações - econômica, política, cultural, ideológica (FAIRCLOUGH, 2001), e a Revisão de Texto se faz presente em todas elas, uma vez que a ordem social que estrutura uma sociedade estabelece-se a partir de um mercado em que os textos são produzidos, distribuídos e consumidos. Em relação a esse mercado, o autor afirma que o primeiro diz respeito a como os textos são produzidos de maneira particular em contextos sociais específicos; o segundo refere-se ao consumo de textos em contextos sociais diversos, variando de acordo com sua natureza; o último explica como os textos são consumidos no mundo, podendo ser distribuídos de forma simples (conversação casual), ou complexa - o texto jornalístico por exemplo. 
Em Discurso e mudança social, Fairclough (2001) discute as características do discurso, contribuindo enormemente para a definição das relações que se estabelecem dentro do texto. Segundo ele o discurso contribui para a construção das identidades sociais, das relações sociais entre as pessoas e de um sistema de conhecimento e crença. Esses três efeitos correspondem, respectivamente, a três funções da linguagem e a dimensões de sentido que coexistem e interagem em todo o discurso.

O autor as denomina funções identitária, relacional e ideacional. Como a atividade de Revisão de Texto lida com vários tipos de discurso, é perfeitamente plausível trazer para essa prática os termos de Fairclough. A partir delas, poder-se-á compreender até onde pode ir o sentido de um texto.

Por função identitária entende-se a maneira como se estabelecem as identidades sociais no discurso, ou seja, o que ajudará a construir o produtor e, posteriormente, o revisor de texto. A função relacional compreende, depois de estabelecidas as identidades, a negociação das relações sociais entre os participantes, como eles chegarão a um acordo de sentido e significado. Por último, a função ideacional explicitará o modo pelos quais os textos representam o mundo, seus processos, entidades e relações; a maneira como se inserem as identidades construídas a partir delas dentro de um contexto.

A importância social da Revisão de Texto, segundo o quadro tridimensional de Fairclough, engloba a prática discursiva. Isso porque ambas, tanto a Revisão de Texto quanto a prática discursiva, são atividades que lidam com gêneros discursivos variados. O revisor trabalha com folders, textos jornalísticos, outdoors etc. Isso comprova que o texto não se restringe ao que se escreve, mas engloba diferentes formas de expressão - imagens, cores - que ajudarão a compor com a parte linguística.

Por fim, o quadro de Fairclough abrange o texto. Ele se encontra "dentro" da prática discursiva por ser caracterizado pelos elementos linguísticos, que são a base da língua. Dessa forma, o texto é o elemento inicial, um meio do qual o sujeito se utiliza para fazer seu discurso. A partir deste, então, ao escolher o gênero a ser 
utilizado para atingir seu objetivo, o sujeito construirá relações entre linguagem, sociedade, poder e identidade, o que o levará à prática social.

Esse trabalho vê e propõe a questão da Revisão de Texto como uma atividade em que há uma negociação de sentido e, ainda, além disso, uma interface entre produtor e revisor, envolvendo inúmeras relações, já que precisará de todos os seus tipos de conhecimento - linguísticos, discursivos e sociais.

Segundo Koch (2004), o processo de produção textual é concebido como atividade interacional de sujeitos sociais, tendo em vista a realização de determinados fins - no caso, a construção de sentido entre produtor e revisor de texto. Ingedore Koch ressalta, ainda que as teorias sócio-interacionais reconhecem a existência de um sujeito planejador/organizador que, em sua inter-relação com outros sujeitos, vai construir um texto, sob a influência de uma complexa rede de fatores, entre os quais a especificidade da situação, o jogo de imagens recíprocas, as crenças, convicções, atitudes dos interactantes, os conhecimentos (supostamente) partilhados, as expectativas mútuas, as normas e convenções sócio-culturais. Isso significa que a construção do texto exige a realização de uma série de atividades cognitivo-discursivas que vão dotá-lo de certos elementos, propriedades ou marcas, os quais, em seu inter-relacionamento, serão responsáveis pela produção de sentidos.

A partir do momento em que tantos elementos cognitivos e discursivos são exigidos, não há como negar as subjetividades presentes na relação produtor/revisor, por isso a necessidade de se enfatizar esse o aspecto discursivo.

\subsection{Ideologia}

A partir do que afirmamos acima, urge que façamos uma iniciação teórica nos pressupostos da ideologia. Voloshinov (BAKHTIN, 1990) escreve o seguinte: "Sem signos, não há ideologia [...]. Tudo é ideológico, logo possui um valor semiótico”. Para ele nem a ideologia, nem a linguagem são fenômenos monolíticos. 
Para Thompson (2000) "Estudar ideologia é estudar as maneiras como o sentido serve para estabelecer e sustentar relações de dominação".

Sendo assim, podemos tentar reunir as duas definições citadas de maneira que podemos imaginar ideologia da seguinte maneira: Ideologia é o conjunto de ideias, conceitos e comportamentos a respeito de um objeto estudado. Na definição de Thompson, quais seriam esses elementos simbólicos de dominação? Segundo ele, um amplo espectro de ações e falas, imagens e textos significativos, imagem visual ou construto que combina imagens e palavras. Desse modo, o conceito de ideologia de Thompson torna-se essencial para a consecução deste trabalho.

\subsection{Teoria dos Gêneros Discursivos ${ }^{3}$}

Depois de vermos os pressupostos da Ideologia, é hora de configurarmos a Teoria dos Gêneros Discursivos, uma vez que nosso corpus é constituído de um Gênero Híbrido. Ainda fazendo uso das citações do livro em questão, Rocha (2005) fala a respeito da Teoria dos Gêneros Discursivos. Cita três importantes nomes na área da linguística. Em primeiro lugar, Bakhtin (1997) afirma que os gêneros discursivos têm íntima relação com a noção de estilo. De acordo com as possibilidades linguísticas, o falante realiza escolhas e imprime sua marca para o contexto e para o interlocutor; em relação aos gêneros discursivos, a situação é semelhante, mas o estilo é coletivo. Determinada cultura possui seus gêneros situados historicamente.

Ele continua sua explanação citando Fairclough (2003) e afirmando que ele amplia a noção do estilo não só para caracterizar os gêneros discursivos, mas também as identidades pessoais e que é interessante vermos que os estilos estão ligados à identificação, ou seja, como as pessoas se identificam e são identificadas por outras. Os estilos são definidos em aspectos linguísticos como: fonológicos, vocabulá-

\footnotetext{
3 A teoria dos gêneros possui abordagens (sociodiscursiva, sociorretórica, sociocognitiva). Focamos, resumidamente, dentro das possibilidades de espaço deste artigo, a primeira abordagem, cujo idealizador é Bakhtin.
} 
rio e metáfora. Para Fairclough, os estilos são aspectos discursivos da forma de ser, quem vocêé, como fala, como você escreve, olha, forma de parar e assim por diante.

Marcuschi (2002) diz que os gêneros textuais são fenômenos históricos, profundamente vinculados à vida cultural e social, apresentando alto poder preditivo e interpretativo das ações humanas em qualquer contexto discursivo. Ele conclui, então, que dessa maneira, todo gênero discursivo deve ser visto como produto do seu tempo e analisado como tal.

Os gêneros discursivos então são formas verbais de ação social relativamente estáveis realizadas em momentos situados em comunidades de práticas sociais em domínios específicos.

\subsection{Multimodalidade}

Ao termos a necessidade de analisar um gênero híbrido nada mais apropriado do que uma teoria que em seu escopo valorize a multissemiose, ou seja, lida com categorias modais amplas, por isso, a Multimodalidade será a nossa última incursão teórica.

Em Discurso Multimodal, Kress e van Leeuwen (2001) têm como intenção descrever como as fontes da Multimodalidade permitem a realização do sentido de muitas maneiras e em diferentes níveis. O texto multimodal, para eles, “[...] é aquele cuja significação realiza-se por meio de vários modos semióticos”, que podem ser: linguagem, narrativa, modalidade escrita, gesto, arranjo espacial, imagens e cor entre outros. Além disso, os autores acreditam que o enfoque multimodal é uma saída de análise mais justa, pois tenta compreender todos os modos de representação social que entram nos gêneros discursivos com a mesma precisão metodológica que $\mathrm{AD}$ ou a $\mathrm{ADC}$ são capazes de lançar no texto.

Assim o interesse não está na análise semiótica convencional, mas nas origens sociais e na produção dos modos e na sua recepção. Já Kress, Leite-Garcia e van Leeuwen (2000), caracterizam o texto multimodal da seguinte maneira: 
a) um conjunto de modos tem suas potencialidades específicas de produção ou leitura de modos;

b) cada modalidade tem suas potencialidades específicas de representação e de comunicação produzidas culturalmente, mas inerentes a cada modo;

c) é preciso compreender a maneira de ler essas produções como coerentes em si mesmas;

d) tanto os produtores quanto os receptores têm poder em relação aos modos semióticos;

e) escritores e leitores produzem signos complexos que emergem do "interesse" do produtor;

f) o "interesse" determina a convergência de um complexo conjunto de fatores: histórias sociais e culturais, contextos sociais e atuais, inclusive estimações do produtor dos signos sobre o contexto comunicativo;

g) o interesse em representações aptas e em uma comunicação efetiva significa que os produtores de signos elegem significantes (formas) apropriados para expressar sentidos, de maneira que a relação entre a um e outro não resulte arbitrária, mas motivadora.

Sendo assim, fica claro que se torna um trabalho insatisfatório, incompleto, interpretar os modos focando somente a língua seja ela escrita ou oral. Um texto multimodal deve ser analisado de maneira ampla e abrangente, que circunde todos os modos semióticos existentes nele.

\subsection{Instrumentos de pesquisa}

O foco desta pesquisa é a análise do trabalho do revisor de texto. Portanto, no questionário a ser utilizado para a pesquisa, centrar-nos-emos em perguntas voltadas diretamente para o revisor.

Começa-se, portanto, definindo o "campo de ação" e o "campo de observação", que pode ser sistemática ou ingênua. O “campo de ação" é o ambiente, ou seja, onde a observação acontecerá e quais serão os sujeitos componentes desse ambiente. Já os “campos de observação" podem ser caracterizados como "campo de observação ingênua”, em que o observador está diretamente envolvido com a atividade a ser analisada. 


\subsection{Categorias analíticas}

Quanto ao delineamento da pesquisa, segundo Bauer e Gaskell (2004), uma cobertura adequada dos acontecimentos sociais exige muitos métodos e dados. A investigação da ação empírica exige a observação sistemática dos acontecimentos, além de inferir os sentidos desses acontecimentos, técnicas de entrevista, interpretação dos materiais analisados etc.

Primeiramente, deve-se distinguir a investigação social que será feita aqui em quatro dimensões: delineamento da pesquisa; métodos de coleta de dados; análise de dados; por fim, interesses de conhecimento. Portanto, o primeiro passo desta pesquisa será fazer um delineamento para coleta de dados. Para tanto, serão utilizados o estudo comparativo (questionário) e a análise de gênero discursivo revisado.

Neste ponto, 3 profissionais (maiores de idade, experientes na área) em atividade de Revisão em setores como empresa jornalística, editora e serviço público contribuirão nesta pesquisa. Um dos instrumentos de pesquisa será a Entrevista Semiestruturada com os seguintes tópicos:

a) Há quantos anos você trabalha como revisor(a)?

b) O que é ser revisor(a) de texto?

c) Qual a finalidade da Revisão de Texto?

d) Como você aprendeu a revisar?

e) Onde você exerce a atividade de revisor(a)?

f) Qual (ais) é (são) a(s) fonte(s) de pesquisa que possibilita(m) seu trabalho?

g) O que você intenciona ao revisar um texto?

Em seguida, os mesmos profissionais serão submetidos a uma revisão de um pequeno gênero discursivo híbrido (produção textual - propaganda impressa - que na sua produção concorrem vários modos semióticos, como imagem, texto, cores) para que se observe o conhecimento crítico multissemiótico desses profissionais na prática.

Terminada essa etapa, segue-se à análise dos dados levantados. Os dados coletados na pesquisa serão avaliados de maneira crítica, buscando atingir o ob- 
jetivo desta pesquisa, que é evidenciar a necessidade das teorias a fim de que se repense a revisão de texto autônoma.

Por meio dessas técnicas, pretende-se ter um controle dos hábitos que norteiam o cotidiano do trabalho do profissional de Revisão de Texto, para, então, chegar a um repensar dessa prática, embora, como dito antes, não se procure por uma verdade absoluta.

\section{Análise dos dados}

O foco desta pesquisa é a análise do trabalho do revisor de texto quanto à natureza gramatical, linguística, discursiva e social. As categorias que serão levantadas da antitese (atividade de revisão ainda voltada para as categorias formais) serão:

1. Há valorização da Gramática Tradicional?

1.2 Há valorização de categorias formais - acentuação, pontuação, concordância, regência?

1.3 Valoriza- se apenas a norma-padrão culta?

2. Há preocupação teórica com base em teorias críticas? - respeito à natureza do gênero discursivo, preocupação ideológica, respeito do contexto; valorização de imagens visuais ou não.

\subsection{Instrumentos de pesquisa}

\subsubsection{Entrevista semiestruturada}

A finalidade para que se evidencie o universo do revisor de texto: tempo de revisão, o que é ser revisor de texto, as bases teóricas que lhes favorecem etc. 


\subsubsection{Revisão de propaganda}

A finalidade deste tópico será confirmar a nossa tese de que a revisão de texto em muitas instituições precisa mudar, modernizar-se, precisa acompanhar as transformações por que está passando a pós-modernidade e suas transformações em linguagem.

\subsection{Colaboradores}

Diversificamos o universo de entrevistados para que se evidenciasse a necessidade de mudança na atividade. Por isso, fomos a campo em três instituições. Os nomes completos dos colaboradores serão mantidos em sigilo por questões éticas.

A professora e Analista Judiciária - MLF do Superior Tribunal de Justiça; a jornalista e revisora - MAG da Editoração Eletrônica do Ministério do Trabalho e Emprego e o superintendente de marketing de publicidade - JASM da área de Jornalismo da empresa Bancorbrás.

A importância desses profissionais consiste no fato de todos terem mais de dez anos atuando de forma direta como revisores, mesmo que em diferentes áreas. Dessa maneira, é possível obter uma análise com respaldo em todos os anos de experiência que cada um desenvolveu no exercício de sua profissão paralelamente à prática da revisão. Isso fatalmente ficará marcado em suas respostas.

\subsubsection{Análise da entrevista semiestruturada}

\section{Entrevistada - STJ (A)}

Possui consciência linguística e discursiva quando respeitou o gênero e seu estilo, inclusive a modalidade informal da linguagem de Ronaldinho. Mas na resposta (b), quando reduz o trabalho de revisar apenas a preparar os originais para publicação, falha, pois revisão não é só isso; (c) suas fontes de pesquisa apenas valorizam estruturas formais. De outra parte, os manuais de estilo dizem respeito apenas à maneira estilística com que publicadores produzem seus gêne- 
ros discursivos; por último, sua última resposta (g) só confirma o que dizemos na letra (a).

Voltando-se à análise da imagem, percebe-se que ela considerou o estilo, mas não interveio nos aspectos multissemióticos como: questionar a falta do colorido, uma vez que esta imagem não se identifica com as produções modernas (a camisa da seleção e a logo do banco precisam de cores); de outra parte, há estruturas linguísticas ininteligíveis - fechamento de aspas na frase de Ronaldo; não se entende o que está escrito abaixo da expressão "Santander Banespa", pior ainda abaixo do mesmo tópico; por último, a imagem está cortada.

\section{Entrevistado - Bancorbrás - Marketing (B)}

Mais uma vez, confirmamos nossas expectativas quanto ao papel do revisor. Na resposta (b), há uma coincidência de resposta com a primeira colaboradora, mas amplia quando o público-alvo deve ser respeitado. Isso significa uma adequação do gênero à situação sociocomunicativa, fato confirmado na resposta (c); na letra (d), sua base teórica reitera o emprego de gramática tradicional como principal instrumento de trabalho na área; a expressão empregada “... leitura e livros especializados” torna a resposta vaga: que leitura? Que livros especializados? Na letra (f), tudo confirma o que se disse da base teórica da letra (d); a letra (g) tornou a perspectiva do revisor entrevistado tautológica, pois se repete nas letras (b) e (c).

$\mathrm{Na}$ análise da imagem, sua preocupação quanto à adequação sociocomunicativa cai por terra. O colaborador aponta erros linguísticos sob a ótica da norma-padrão culta que não podem ser levantados no gênero sob análise: Ele considera a forma abreviada "pro" como inadequada para o contexto, como se não fosse adequada à personagem representada e à linguagem utilizada pelo marketing do Banco a fim de atingir o grande público. Além disso, não entendeu a ambiguidade provocada pelo emprego de caixa alta e baixa no sintagma "banco do Brasil", em que o concorrente tenta fragmentar a imagem do Banco do Brasil por meio desse jogo. Não falta ética, pois ninguém poderia afirmar que o Santander teve a inten- 
ção. Além do mais "banco" pode ter tantos sentidos - banco-de-reserva, instituição Banco do Brasil e por último, um Banco Brasileiro, instituição qualquer.

Discordamos do colaborador quando afirma que falta conceito à propaganda. A imagem de Ronaldo, O Fenômeno, está adequada aos propósitos do Santander. À época da Copa era o número 1, posição confirmada pelo dedo-indicador. Hoje, óbvio, sua imagem não estaria adequada.

\section{Entrevistada - Editoração - Gráfica (C)}

Por último, não necessariamente diferente, temos os resultados da profissional de gráfica. Passemos como sempre às respostas inicialmente, para, depois, à "Revisão" da imagem.

Coroa-se o que já esperávamos. Ser revisor de texto (letra a) para ela é uma atividade eminentemente mecânica, fria, muito pouco discursiva, autônoma - adequar isso àquilo, checar, padronizar... A resposta (c) em nada difere das outras. A mudança em sua resposta está em situar tanto logicamente a função da ABNT como uma camisa de força que serve para tudo.

Um ponto a assinalar é o emprego sistemático da palavra "Gramática" em todos os questionários, todos possuem o sentido mais recorrente. Gramática significando a Gramática Tradicional, e os múltiplos sentidos da palavra em uma perspectiva linguística - gramática como sistema, conjunto de regras, gramática como uma língua particular que possui suas regras de organização.

$\mathrm{Na}$ letra (f), tudo se repete; não há uma obra de cunho linguístico como base para revisar. Na última resposta, o que ela amplia é a preocupação com a editoração do texto, o que para nós é louvável, uma vez que o processo de formação vai muito além das normas gramaticais.

$\mathrm{Na}$ análise da propaganda, pela terceira vez, o código imagético ficou fora das considerações. Nem foi cogitado. O foco foram as categorias linguísticas, e 
mesmo assim uma análise redutora, ínfima. Ela corrigiu a contração "pro" para as opções (ao) ou (para o). Dentro das “adequações", deu-nos os sentidos de suas escolhas: Para o = quando vai para ficar; ao = quando vai de passagem (SIC).

Deixar de lado os aspectos híbridos - aspectos linguísticos, as possibilidades de sentido da frase de Ronaldinho, o nível de linguagem empregado, o uso das aspas dando autoria a Ronaldo e eximindo o Banco de possíveis processos. É uma prática semioticamente redutora.

\subsubsection{Análise do gênero propaganda à luz das teorias críticas}

Quanto à análise do gênero discursivo apresentado, não há revisão alguma a ser feita. Na contraparte linguística, que contribui hibridamente para a construção da produção sob foco, temos poucos exemplos “passíveis” de análise. Na frase supostamente proferida por Ronaldo "Eu nunca fui pro banco do Brasil", temos um reforço necessário entre o pronome-do-caso-reto-sujeito e o verbo. Por quê? "Nunca fui pro banco do Brasil" não surtiria o mesmo efeito que o período completo, com o pronome-sujeito.

O emprego das aspas é outro recurso redundante discursivo interessante. Se há a assinatura de Ronaldo logo abaixo da frase, marcando a autoria, não haveria a necessidade das aspas. Se houvesse apenas as aspas, a autoria seria marcada pela personagem da imagem. Discursivamente, isso tem sua importância: o Santander não assume a fala e a atribui ao garoto-propaganda. Se houver processo pela falta de ética do Santander, este poderá se eximir, atribuindo a culpa ao jogador.

Tudo isso é provocado pela ambiguidade estabelecida no sintagma "banco do Brasil" ao se empregarem iniciais maiúsculas e minúsculas. A palavra "banco" pode significar: banco-reserva, banco instituição, ir ao Banco do Brasil, ir ao banco do Brasil é ficar na reserva (em um nível bem mais subjacente).

O coloquialismo da frase está adequado ao nível linguístico de um jogador que não domina a norma-padrão culta e agrada as massas - pelo menos à épo- 
ca da Copa em 2006. Esse coloquialismo fica marcante no emprego abreviado da preposição "para" (para + o = pro), cujo emprego pode variar nas seguintes possibilidades de uso linguístico: para/pro Banco do Brasil; para ou pro banco-reserva; ao Banco do Brasil; mas não poderíamos empregar “ao banco-reserva”, não-usual.

Quanto às outras estruturas linguísticas, temos três períodos que carecem de maior nitidez de imagem, cuja solução só se resolve aumentando a quantidade de pixels da fotografia, ou escaneando com 300 pixels ou mais. Nesse caso, o revisor deve pedir mais clareza, para que não ocorra erro de interpretação, causado por ruídos de editoração. Só conseguimos entender o logotipo da empresa e o sintagma "Santander Banespa". O mesmo deve ser feito quanto ao fechamento das aspas da frase "Eu nunca fui pro banco do Brasil. Mais uma vez, o revisor deve pedir o reenquadramento da imagem para que não se perca seu conteúdo linguístico e imagético - e mais ainda o discursivo.

Na análise da imagem propriamente dita, falta cor. Não se justificaria uma foto produzida na pós-modernidade e com tantos recursos visuais e tecnológicos apresentar-se aos "consumidores" com tal estilo. Em anexo, consta essa imagem como foi produzida. Colocamo-la em preto e branco como uma forma de provocar o revisor sobre a importância de se considerar a análise imagética na revisão de texto híbrido.

Quando pedimos para os revisores "revisarem" a propaganda, todos deixaram completamente de lado a imagem, e se preocuparam com estruturas linguísticas. Dois tentaram adequá-las à norma-padrão culta. De acordo com as teorias críticas, notadamente a gramática visual, a análise da imagem poderá ser realizada da seguinte maneira: temos uma imagem com um único personagem representado. Isso torna a imagem intransitiva, pois não há outros personagens na foto. Essa intransitividade dá mais força à imagem. Isso, aliado ao fundo desfocado que a realça mais intensamente. Quanto ao processo reacional, o garoto-propaganda, sorrindo, olha para nós, os viewers, e nos convida a participar de sua felicidade. Seu olhar e sorrisos tornam-nos mais íntimo - há maior interação.

O dedo indicador em riste é polissêmico em múltiplas instâncias: pode significar que o Santander é o número 1, “o Santander me escolheu porque sou o 
número 1, logo minha posição coincide com a do Banco"; essa posição do dedo também indica um gol, gesto que se repete toda vez que o faz.

\section{Conclusão}

Nosso objetivo nessa pesquisa foi repensar a atividade de Revisão de Texto autônoma em uma perspectiva crítica para acompanhar as novas mudanças nos estudos da linguagem. A atividade de revisão realizada nos dias de hoje, linguisticamente redutora e praticada em muitos contextos institucionais como demonstramos aqui, em que o foco ainda se baseia em "corrigir" um texto apenas calcando-se na modalidade escrita, e deixando de lado as riquezas linguísticas e estilísticas do gênero a ser revisado.

Nosso primeiro objetivo de pesquisa foi situar a Revisão de Texto que se pratica ainda em empresas jornalística, editora, gráfica e serviço público. Respondemos a primeira questão no primeiro capítulo em que evidenciamos que esta prática é discursivamente redutora.

Em segunda instância, tivemos, como objetivo de pesquisa, comparar a Revisão de Texto Tradicional e a Revisão de Texto Crítica. Essas teorias foram apresentadas no segundo capítulo quando trouxemos as bases que deram suporte às transformações que pretendíamos quanto à revisão de texto clássica. A incursão feita pelo pensamento dos teóricos permitiu-nos concluir que a concepção de linguagem tem mudado radicalmente, e a revisão autônoma não tem evoluído com essas mudanças. Primeiro, a revisão de texto é uma prática social, com todas as implicações discursivas e ideológicas. Quando as pessoas produzem um texto possuem uma intenção, querem transformar algo ou alguém, ou até o mundo. Todo gênero discursivo produzido não é apenas um meio de comunicação. Pensar assim é reduzir a riqueza de nossas produções textuais, tão complexas linguística, cognitiva, ideológica e socialmente.

Como terceiro e quarto planos, nosso intuito foi o de explanar qual seria nosso método de pesquisa, os instrumentos utilizados para tal e situar a revisão de 
texto que se aplica ainda em serviço público, gráfica e empresa jornalística, respectivamente, a partir de instrumentos como: entrevista semiestruturada e revisão de gênero híbrido. Percebemos que os colaboradores mantêm-se inseridos em uma revisão de texto monomodal que exalta apenas estruturas formais, e não se preocupam com outras formas de linguagem. Suas noções de linguagem são muito restritas.

Sendo assim, concluímos que ser revisor de texto não é uma tarefa simplória encarada por muitos como uma atividade eminentemente mecânica, fria, muito pouco discursiva, autônoma - adequar isso àquilo, checar, padronizar, preocupar-se em aplicar corretamente regras fornecidas por gramáticas ou manuais de redação.

O propósito deste trabalho está em questionar, repensar esta atividade que, engessada na prática monomodal, desconsidera aspectos fundamentais que a pós-modernidade nos trouxe a exemplo da Multimodalidade.

Assim, as considerações apresentadas em todo nosso trabalho podem ser vistas como uma contribuição para uma nova perspectiva a respeito da prática da revisão de texto, no sentido de alterar as mudanças recorrentes na sociedade contemporânea; sendo assim, faz-se necessária uma reformulação nos conceitos do que é ser revisor de texto. O mundo está se transformando, e nós não percebemos essa transformação nos meios de comunicação.

Admitimos que essa "discussão" é apenas um começo, mesmo porque futuros projetos e pesquisas nessa área devam ser desenvolvidos e posteriormente aplicados. O que galgamos é revelar a importância de nosso trabalho para gerar transformações nesse tipo de atividade com base na Teoria da Linguística Crítica, transformando, assim, uma nova era no aspecto profissional da Revisão de Texto. 


\section{From text revision to critical text revision: a new professional perspective}

Abstract

Text Revision is not just to suit and revise the proper genre to the pattern of the Portuguese language. Thinking like that makes the activity superficial, once that practice is inserted in a subjectivity whose elements are more complex. That the importance of this work to contribute to the changing of the Text Revision in a critical perspective. Therefore, Text Revision has a social function. Thus, this must be considered, indeed, as a practice which reaches horizons that goes beyond the written text. Being like this, the practice needs to be analyzed from visions macro that regard the relations stemmed from that activity - between language and society, language and power, language and identity. In this way, my goal is to rethink the Text Revision activity in a critical perspective to follow the new changes in the studies of the language and apply them in the activities related to text analysis. The theoretical fundamentation used is based especially in the Critical Discourse Analysis (CDA), in the works of Fairclough $(2001,2003)$, in the Theory of the Discursive Genres, Bakhtin (1997) and Marcuschi (2002).

Keywords: Professional text revision. Critical theory. Activity. Multimodality.

\section{Referências}

BAKHTIN, M. Estética da criação verbal. Tradução de Maria Galvão Gomes Pereira. São Paulo: M. Fontes, 1997.

BAUER, M.W.; GESKELL, G. Para uma prestação de contas pública: além da amostra, da fidedignidade e da validade. In: (Org.). Pesquisa qualitativa com texto, imagem e som: um manual prático. Petrópolis: Vozes, 2002.

BAUER, M.W.; GESKELL, G. Pesquisa qualitativa. Contexto, imagem e som. Petrópolis: Vozes, 2003.

CHARAUDEAU, P.; MAINGUENEAU, D. Dicionário de análise do discurso. São Paulo: Contexto, 2004. 
CUNHA, Celso; CINTRA, Lindley. Gramática do português contemporâneo. Rio de Janeiro: Nova Fronteira, 1985.

FAIRCLOUGH, N. Discurso e mudança social. Trad. Maria Izabel Magalhães. Brasília: UNB, 2001.

FAIRCLOUGH, N. Analysing discourse: textual analysis for social research. London: Routledge, 2003.

FAIRCLOUGH, N. Discourse and social change. Cambridge: Polity Press, 1992.

FLICK, Uwe. Uma introdução à pesquisa qualitativa. São Paulo: Bookman, 2004.

GNERRE, Maurizio. Linguagem, escrita e poder. São Paulo: M. Fontes, 1994.

HOUAISS, A. et al. Dicionário Houaiss da Língua Portuguesa. Rio de Janeiro: Objetiva, 2001.

KRESS, Gunther; LEITE-GARCIA, R.; VAN LEEUWEN, Theo. Semiótica discursiva. In: VAN DIJK, Teun A. (Comp.) El discurso como estructura y processo estudios sobre el discurso: una introducción multidisciplinaria.. Espanha: Gedisa, 2000. p. 335-372.

KRESS, Gunther; VAN LEEUWEN, Theo. Multimodal discourse: the modes and media contemporary communication. New York: Oxford, 2001.

KOCH, Ingedore G. V. Introdução à linguística textual. São Paulo: M. Fontes, 2004.

MACHADO, Ida Lúcia; Renato de Mello (Org.). Gêneros: reflexões em análise do discurso. Belo Horizonte: NAD/POSLIN/FALE-UFMG, ano?.

MARCUSCHI, Luiz A. Gêneros textuais: definição e funcionalidade. In: DIONÍSIO, Ângela P. et al. (Org.). Gêneros textuais \& ensino. Rio de Janeiro: Lucerna, 2002.

PEDRO, Emilia Ribeiro (Org.). Análise crítica do discurso. Lisboa: Caminho, 1997.

RAJAGOPALAN, Kanavillil. Por uma lingüística crítica: linguagem, identidade e a questão ética. São Paulo: Parábola, 2003.

ROCHA, Harrison. Reflexões sobre a Língua Portuguesa: uma abordagem multimodal. Petrópolis: Vozes, 2005. 
SILVA, Denise Elena Garcia da; VIEIRA, Josênia Antunes (Org.). Análise do discurso: percursos teóricos e metodológicos. Brasília: Plano, 2002.

THOMPSON, John B. Ideologia e cultura moderna: teoria social crítica na era dos meios de comunicação de massa. Petrópolis: Vozes, 2000.

\section{Anexo}

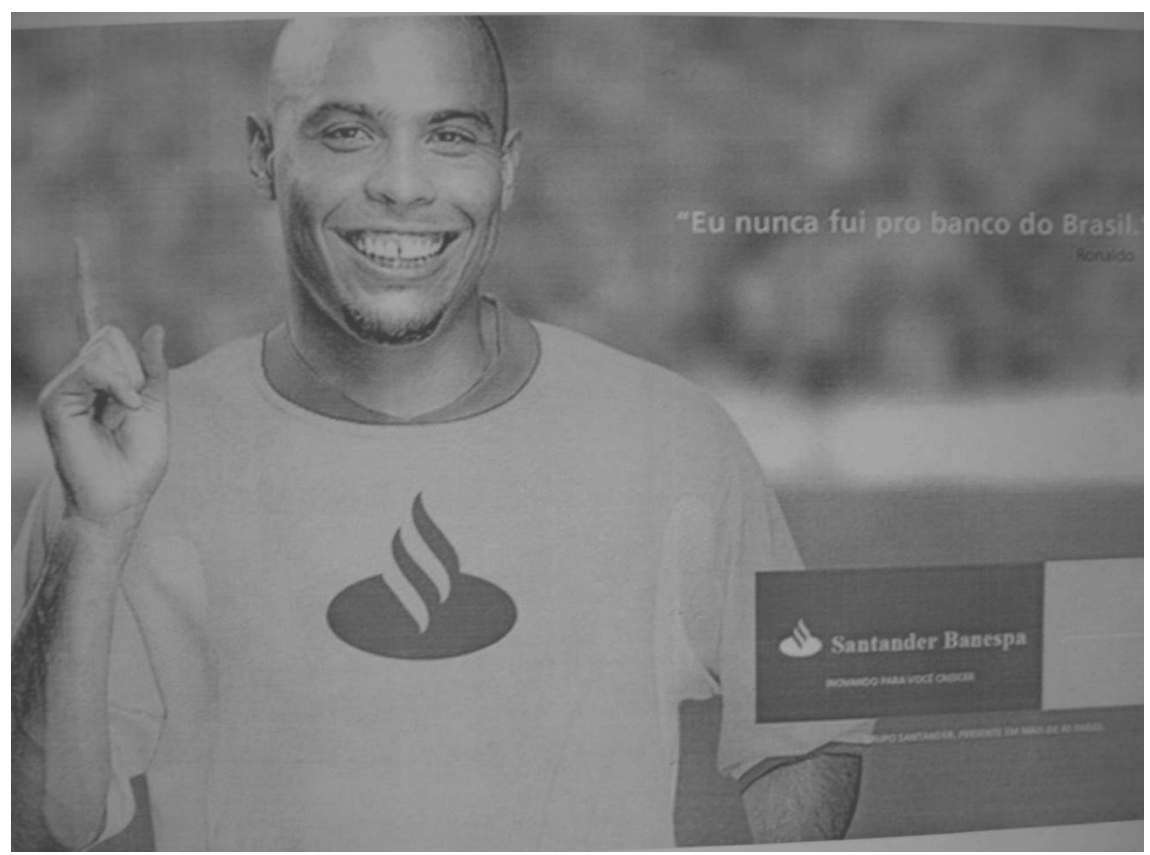




\section{Para publicar na revista Universitas Humanas, acesse 0 endereço eletrônico www.publicacoesacademicas.uniceub.br. Observe as normas de publicação, para facilitar e agilizar o trabalho de edição.}

